\title{
DEFINICÃO DE REGIÕES HIDROLOGICAMENTE HOMOGÊNEAS A PARTIR DE TÉCNICAS DE ESTATÍSTICA MULTIVARIADA NA BACIA HIDROGRÁFICA DO RIO ITAPICURU - BA COM BASE EM DADOS FÍSICO-CLIMÁTICOS E DE SENSORIAMENTO REMOTO
}

\author{
Ytallo Rafaell Teixeira de Albuquerque \\ Universidade Federal do Rio Grande do Sul \\ Pós-Graduação em Minas, Metalúrgica e Materiais, Porto Alegre, RS, Brasil \\ ytallorafaell@yahoo.com.br \\ André Quintão de Almeida \\ Universidade Federal de Sergipe \\ Centro de Ciências Agrárias Aplicadas, Departamento de Engenharia Agrícola, São Cristóvão, SE, Brasil \\ andreqa@gmail.com \\ Mariana Stocco Arcier \\ Universidade Federal de Sergipe \\ Pós-Graduação em Recursos Hídricos, São Cristóvão, SE, Brasil \\ engmarianasa@gmail.com \\ Ludmilson Abritta Mendes \\ Universidade Federal de Sergipe \\ Centro de Ciências Exatas e Tecnologia, Departamento de Engenharia Civil, São Cristóvão, SE, Brasil \\ ludmilsonmendes@yahoo.com.br
}

\begin{abstract}
RESUMO
A pouca informação fluviométrica relacionada à inconsistência espaço-temporal de dados históricos disponíveis, tem resultado em grande restrição para se representar a dinâmica dos recursos hídricos em estudos hidrológicos, principalmente das vazões. Nesse contexto, buscam-se metodologias para estimar a vazão em locais sem monitoramento. Dessa forma, o objetivo desse trabalho foi identificar regiões hidrologicamente homogêneas na Bacia Hidrográfica do Rio Itapicuru (BHRI), localizada ao nordeste do Estado da Bahia, via técnica de análise de agrupamento, através do método clustering híbrido k-means hierárquico, utilizando a distância como medida de similaridade a partir de variáveis físico-climáticas e de relevo. Foram definidas três regiões hidrologicamente homogêneas na bacia hidrográfica com base nas variáveis explicativas: precipitação, evapotranspiração, relação precipitaçãoevapotranspiração, área e índice de vegetação de diferença normalizada - NDVI. O algoritmo do método proposto mostrou-se eficiente para o agrupamento dos dados utilizados, onde foi possível encontrar as características de cada cluster formado, sem haver sobreposição de dados nos intervalos das variáveis analisadas. Por fim, essas regiões auxiliarão em estudos de regionalização e contribuirão para o planejamento e gestão dos recursos hídricos.
\end{abstract}

Palavras-chave: Análise Multivariada. Cluster. Hierárquico.

\section{DEFINITION OF HYDROLOGICALLY HOMOGENEOUS REGIONS FROM MULTIVARIATE STATISTICAL TECHNIQUES IN THE ITAPICURU RIVER BASIN - BA BASED ON PHYSICAL-CLIMATIC AND REMOTE SENSING DATA}

\begin{abstract}
Few information about fluviometric related to the time-space inconsistency of historical data available has resulted in great restriction to represent the dynamics of water resources in hydrological studies, especially the flow rates. In this context, methodologies to estimate the flow in places without monitoring are searched. Thus, the objective of this work was to identify hydrologically homogeneous regions in the Itapicuru River Basin (BHRI), located in the northeast of the State of Bahia, through the cluster analysis technique, using the hierarchical hybrid k-means clustering method, using the distance as similarity measure from physical-climatic and relief variables. Three hydrologically homogeneous regions were defined in the proposed watershed based on the explanatory variables: precipitation, evapotranspiration, precipitation-evapotranspiration ratio, area and normalized difference vegetation index - NDVI. The algorithm of the proposed method proved to be efficient for the used data grouping, where it was possible to find the characteristics of each cluster formed, without overlapping data in the intervals of the analyzed variables. Finally, these regions will support the regionalization studies and contribute to the planning and management of water resources.
\end{abstract}

Keywords: Multivariate analysis. Cluster. Hierarchical.

$\begin{array}{lllll}\text { Caminhos de Geografia } \quad \text { Uberlândia-MG } & \text { v. 21, n. } 78 & \text { Dez/2020 } & \text { p. 290-302 Página } 290\end{array}$


Definição de regiões hidrologicamente homogêneas a partir de técnicas de estatística multivariada na Bacia Hidrográfica do Rio Itapicuru - BA com base em dados físico-climáticos e de sensoriamento remoto
Ytallo Rafaell Teixeira de Albuquerque André Quintão de Almeida Mariana Stocco Arcieri Ludmilson Abritta Mendes

\section{INTRODUÇÃO}

A disponibilidade de vazão em uma bacia é um fator determinante para quantificar, entre outros, a disponibilidade hídrica ou dos excedentes de vazões, onde o seu conhecimento é indispensável e fundamental para o planejamento e a gestão dos recursos hídricos (BRASIL, 1997; PESSOA, 2015). No entanto, um dos problemas que se apresentam em estudos relacionados às vazões é a falta de monitoramento fluviométrico, que acarreta a falta de informação ao longo do tempo nas bacias hidrográficas. As regiões Norte e Nordeste do Brasil, por exemplo, apresentam uma rede pouco densa de estações hidrológicas, o que compromete os estudos de planejamento e gestão dos cursos d'água dessas regiões

Desse modo, para tentar preencher a ausência de dados, o desenvolvimento de modelos de simulação de vazões, em bacias sem monitoramento, tem se tornado muito comum. Dentre as mais diversas técnicas, têm se destacado os estudos de regionalização de vazões, utilizados principalmente em estudos de outorga dos direitos de uso dos recursos hídricos. Este método consiste na utilização de um conjunto de ferramentas que busca realizar a transferência de informações de uma região que apresenta dados para outra região que não possui dados, com o intuito de suprir essa carência de informação em uma dada região considerada homogênea (NERC, 1975; ELETROBRÁS, 1985; EUCLYDES et al., 2001; CHAVES et al., 2002; SILVA, 2018).

Considerada uma das etapas iniciais no desenvolvimento da regionalização, a identificação de regiões homogêneas pode ser realizada por diversas formas, por exemplo, através de funções de probabilidade, análise de agrupamento, entre outros. A identificação de regiões homogêneas, quanto às suas características físicas e climáticas, pode ser realizada de acordo com duas finalidades: a primeira, descritiva, cujo objetivo é a caracterização hidrológica, e a segunda, como subsídio essencial na regionalização (GOMES et al., 2018).

Assim, diversos trabalhos de identificação de regiões homogêneas têm sido realizados, no mundo inteiro, objetivando a aplicação da regionalização, como nos trabalhos de Srinivas et al. (2008) e Rao e Srinivas (2006) que obtiveram as regiões homogêneas de vazões de Indiana, Estados Unidos, através de dados anuais máximos de fluxo das bacias hidrográficas.

Umas das técnicas comumente utilizadas na hidrologia para se definir regiões hidrologicamente homogênas é a análise estatística multivariada de agrupamento, também conhecida como análise de cluster (PESSOA, 2015; SILVA, 2018). Nesta técnica, as regiões homogêneas são definidas com base na similaridade de suas características hidrológicas, como, os aspectos (i) físicos: relevo, altitude, área de drenagem, tipo de vegetação, entre outros; e (ii), hidrológicos, como as precipitações e o comportamento das vazões (SILVA, 2018). Segundo Moraes (2016), os métodos de agrupamento podem ser divididos em hierárquicos, que constroem uma hierarquia semelhante a uma árvore, feita em partições, onde há relacionamentos entre os elementos; e não-hierárquicos ou particionais, que constroem uma partição dos dados, dividindo os objetos em grupos, sem sobreposição, tomando por base as características que estes objetos possuem. De modo geral, a análise de agrupamento trabalha na separação de elementos com características distintas (heterogeneidade externa) e na união de grupos com elementos que possuem características comuns (homogeneidade interna). Essa análise faz a organização dos dados que servirão para auxiliar o processo de construção da superfície de decisão e determinar qual a região de influência de cada grupo de dados, tornando-se uma ferramenta muito útil para a análise de dados em diversas situações (LINDEN, 2009).

Apesar do elevado número de estudos de definição de áreas homogêneas para fins de regionalização de vazões, poucos ainda são aqueles que utilizam de dados de sensoriamento remoto (SR), como os dados do Índice da Diferença Normalizada da Vegetação (NDVI), que permite observar o comportamento da vegetação na superfície terrestre ao longo do tempo (EMBRAPA, 2016). Assim, o objetivo deste trabalho foi identificar regiões hidrologicamente homogêneas na Bacia Hidrográfica do Rio Itapicuru - BA através de análise estatística multivariada de agrupamento, a partir de características físico-climáticas e dados de sensoriamento remoto.

\section{METODOLOGIA}

\section{Área de Estudo}

A bacia do rio Itapicuru (BHRI) está localizada na região nordeste da Bahia (Figura 01) e possui uma área $38.664 \mathrm{~km}^{2}$, representando $6,60 \%$ do Estado. Sua população ultrapassa 1,4 milhão de

$\begin{array}{lllll}\text { Caminhos de Geografia } & \text { Uberlândia-MG } & \text { v. 21, n. } 78 & \text { Dez/2020 } & \text { p. 290-302 }\end{array}$ Página 291


Definição de regiões hidrologicamente homogêneas a partir de técnicas de estatística multivariada na Bacia Hidrográfica do Rio Itapicuru - BA com base em dados físico-climáticos e de sensoriamento remoto
Ytallo Rafaell Teixeira de Albuquerque André Quintão de Almeida Mariana Stocco Arcieri Ludmilson Abritta Mendes

habitantes, representando $10,05 \%$ do total do Estado, possuindo uma economia voltada à atividade mineradora e predomínio da agricultura de subsistência e pecuária tradicional (IBGE, 2011; INEMA, 2018). A BHRI limita-se ao norte com as bacias do rio Real e rio Vaza Barris, a oeste com a bacia do rio São Francisco, e ao sul com as bacias do rio Paraguaçu e rio Inhambupe (CRA, 2001).

O rio Itapicuru, o principal curso de água, deu o nome à bacia, ele nasce a oeste, no município de Campo Formoso, no piemonte da chapada Diamantina, a 766,0 m de altitude, percorrendo 534,8 km até desaguar no oceano Atlântico, no município do Conde. Seus principais afluentes são os rios Itapicuru-açu, com nascente no município de Pindobaçu, Itapicuru-mirim com nascente no município de Miguel Calmon, e rio do Peixe em Capim Grosso, todos estes na margem direita do Itapicuru, ao todo 55 municípios integram parcial ou integralmente a BHRI (VIRÃES, 2013; INEMA, 2018).

A bacia apresenta um clima semi-árido em $81 \%$ da área, com chuvas anuais inferiores a $700 \mathrm{~mm}$. $\mathrm{Na}$ parte superior da região, na Chapada da Diamantina, o clima torna-se mais ameno, mudando para o tipo subúmido a seco, com os totais pluviométricos atingindo até $\quad 900 \mathrm{~mm}$. No trecho inferior da bacia do Rio Itapicuru o clima muda para o tipo úmido a subúmido com precipitações variando de 1000 até $1400 \mathrm{~mm}$. Seu relevo é, predominantemente, mais suave, possuindo os seguintes ambientes hidrológicos: $18,8 \%$ da área em relevo plano; $43,2 \%$ em relevo suave ondulado; ondulado abrange $27,7 \%$; ondulado $8,1 \%$; e apenas $2,2 \%$ da área apresentam relevo entre montanhoso e forte montanhoso (VIRÃES, 2013).

Figura 1 - Aracaju (SE): Localização da Bacia do Rio Itapicuru, 2019.

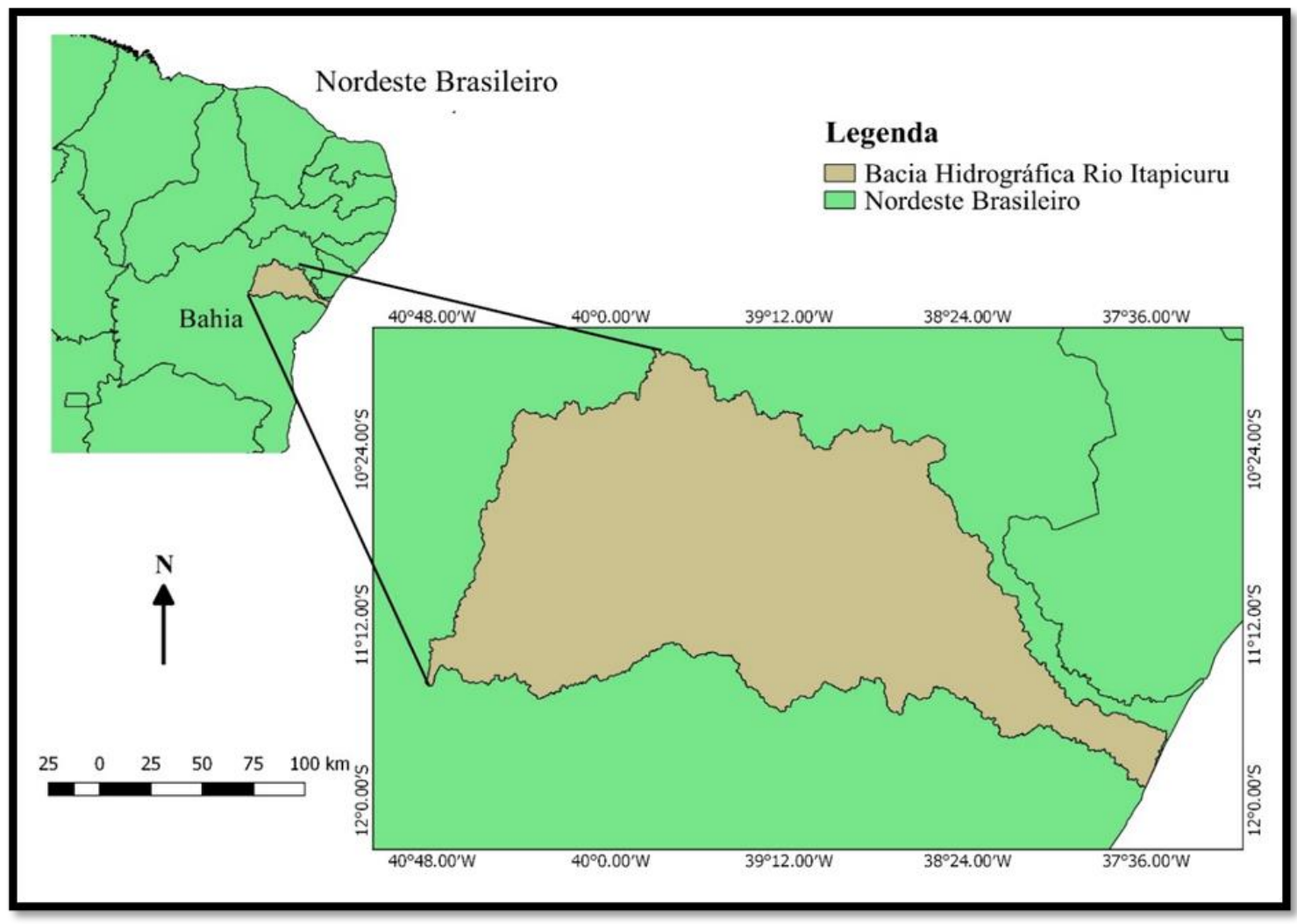

Fonte - Autores (2019).

Quanto à cobertura vegetal, em sua parte superior, no Pediplano da Chapada da Diamantina, encontram-se os remanescentes de florestas estacionais e campos rupestres; em sua parte central, abrange as depressões periféricas e interplanálticas, e a bacia sedimentar de Tucano, onde há a predominância de pastagens entremeadas por áreas com vegetação de Caatinga; o seu trecho final encontra-se sobre o Planalto Costeiro onde ocorrem espécies florestais secundárias da Mata Atlântica (INEMA, 2018). 
Definição de regiões hidrologicamente homogêneas a partir de técnicas de estatística multivariada na Bacia Hidrográfica do Rio Itapicuru - BA com base em dados físico-climáticos e de sensoriamento remoto
Ytallo Rafaell Teixeira de Albuquerque André Quintão de Almeida Mariana Stocco Arcieri Ludmilson Abritta Mendes

\section{Base de Dados Climáticos}

Os dados climáticos foram obtidos a partir do estudo realizado por Xavier et al. (2015), utilizando os dados históricos (1980 a 2013) diários de precipitação pluvial (P) e evapotranspiração potencial (ET0) de 82 pontos de grade inseridos no contexto da bacia, todos em milímetros (Figura 02). A partir destes, a relação entre P e ETO também foi estimada. No estudo, os autores utilizaram um conjunto de dados meteorológicos pontuais coletados em estações convencionais e automáticas distribuídas em todo território nacional durante o período de 1 de janeiro de 1980 a 31 de dezembro de 2013. A partir dos dados pontuais de clima e técnicas de interpolação espacial, uma grade densa de pontos $\left(0,25^{\circ} \times 025^{\circ}\right)$ foi gerada para todo o continente brasileiro, contendo valores diários de temperatura e umidade relativa do ar, precipitação, evapotranspiração, velocidade do vento e radiação solar. A evapotranspiração foi estimada com base na equação de Penman-Monteith (ALLEN et al., 1998).

Figura 2 - Aracaju (SE): Distribuição espacial dos pontos de grade de dados climáticos, metodologia de Xavier et al. (2015), inseridas na BHRI, 2019.

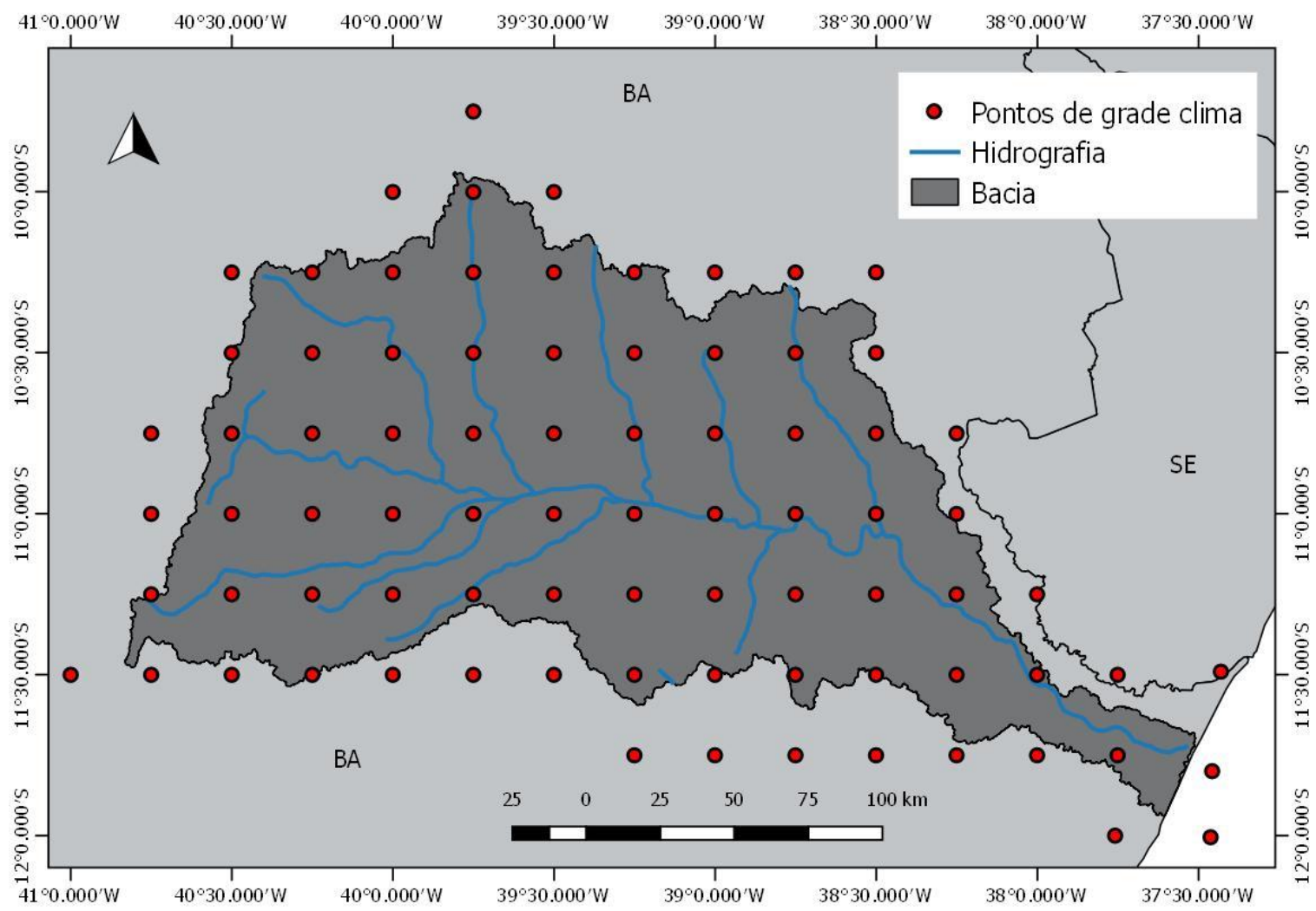

Fonte - Autores (2019).

\section{Características de Solos}

O solo constitui-se como um fator fundamental para o processo de infiltração, essencial para a recarga de aquíferos. Características como estrutura e textura do solo influenciam diretamente na condutividade hidráulica (MORAIS, 2012).

As classes de solo que predominam na região da Bacia hidrográfica do Rio Itapicuru, são as classes dos Planossolos, Latossolos e Argissolos, com ocorrência de Neossolos, Cambissolos, dentre outras classes (PURIFICAÇÃO et al., 2016).

\section{Dados de Relevo}

Os dados de altitude para cada ponto de grade climática foram extraídos do Modelo Digital de

Caminhos de Geografia $\quad$ Uberlândia-MG $\quad$ v. 21, n. 78 $\quad$ Dez/2020 $\quad$ p. 290-302 Página 293


Definição de regiões hidrologicamente homogêneas a partir de técnicas de estatística multivariada na Bacia Hidrográfica do Rio Itapicuru - BA com base em dados físico-climáticos e de sensoriamento remoto
Ytallo Rafaell Teixeira de Albuquerque André Quintão de Almeida Mariana Stocco Arcieri Ludmilson Abritta Mendes

Elevação (MDE) obtido pela Shuttle Radar Topography Mission (SRTM). Com resolução espacial de $90 \mathrm{~m}$ e escala equivalente a 1:250.000 (SREEDEVI et al., 2009), estes dados estão disponíveis no site da Agência Espacial Americana (NASA).

Para a composição de toda a área de estudo, foram baixadas 13 cenas SRTMs, do Estado da Bahia, compatíveis com as folhas na escala 1:250.000 do IBGE, sendo: SC-24-V-C, SC-24-V-D, SC-24-X-C, SC-24-Y-A, SC-24-Y-B, SC-24-Z-A, SC-24-Y-C, SC-24-Y-D, SC-24-Z-C, SE-24-Z-D, SD-24-V-A, SD24-V-B, SD-24-X-A (EMBRAPA, 2018).

O software utilizado para manipulação das imagens SRTM foi o Quantum GIS (QGIS) 2.18.14 Las Palmas (QGIS DEVELOPMENT TEAM, 2019).

\section{Dados de sensoriamento remoto (SR)}

O Índice da Vegetação (IV) derivado de um sensor remoto orbital utilizado neste estudo foi o Normalized Difference Vegetation Index, NDVI, a abreviação da expressão em inglês (ROUSE et al., 1973) que equivale em português a Índice de Vegetação da Diferença Normalizada. Este índice realça o componente espectral da vegetação por meio da combinação das bandas espectrais do vermelho (V) e do infravermelho próximo (IVP) (Equação 01). Sendo mais sensíveis às variações da estrutura do dossel do que as bandas individuais do sensor, podendo variar de -1 , áreas sem vegetação e +1 , áreas com vegetação.

$$
N D V I=\frac{(I V P-V)}{(I V P+V)}
$$

Em que,

V: banda espectral do vermelho; e

IVP: banda espectral do infravermelho próximo.

Este índice está disponível em uma ferramenta gratuita desenvolvida pela Embrapa Informática Agropecuária, chamada Sistema de Análise Temporal da Vegetação (SATVeg). Este sistema se destina à observação e análise dos seus perfis temporais de NDVI, permitindo ao usuário observar o comportamento da vegetação na superfície terrestre ao longo do tempo (EMBRAPA, 2016). As séries de dados NDVI foram baixadas da plataforma da EMBRAPA para cada um dos 82 pontos de grade climático inserido na bacia. As imagens obtidas são provenientes do sensor Moderate Resolution Imaging Spectroradiometer (MODIS) a bordo dos satélites Terra e Aqua. Nestes, os NDVIs são disponibilizados em composições máximas de 16 dias, com resolução espacial de aproximadamente $250 \mathrm{~m}$.

A compatibilização dos dados de clima e NDVI foi procedida através do cruzamento das escalas espaciais, capturando-se os valores de NDVI da célula em que se encontrava os pontos da grade climática, resultando em valores de clima e vegetação para um mesmo ponto da grade. Quanto à escala temporal, os dados climáticos compreenderam as médias mensais da série histórica de 1980 a 2013 e os dados de NDVI, as médias mensais dos dois valores a cada 16 dias da série histórica de 2000 a 2017.

\section{Análise de Agrupamento}

Foram considerados na análise de agrupamento os dados físico-climáticos da bacia para cada ponto de grade contendo altitude, precipitação pluvial, evapotranspiração potencial e a relação entre a chuva e a evapotranspiração. Além destas informações, também foram utilizados os valores de NDVI compatibilizados em escala espaço-temporal para cada ponto de grade. Para a determinação das regiões hidrologicamente homogêneas, foi utilizada a combinação dos métodos de análise de agrupamento clustering hierárquico e k-means, uma aplicação fornecida usando ferramentas através do software $R$ (R CORES TEAM, 2015). Esse processo é denominado clustering híbrido $k$-means hierárquico ou hkmeans (GALILI, 2016).

O procedimento realizado foi dividido em: (i), computou-se o agrupamento hierárquico e aplicou-se o 
Definição de regiões hidrologicamente homogêneas a partir de técnicas de estatística multivariada na Bacia Hidrográfica do Rio Itapicuru - BA com base em dados físico-climáticos e de sensoriamento remoto
Ytallo Rafaell Teixeira de Albuquerque André Quintão de Almeida Mariana Stocco Arcieri Ludmilson Abritta Mendes

corte na árvore em k-clusters; (ii), calculou-se o centro de cada cluster; e (iii), calculou-se k-means usando o conjunto de centros de cluster como os centros de cluster iniciais. Este método baseou-se no critério maior distância para fazer a segregação dos grupos, compostos por 82 pontos da grade de dados climáticos inseridos na bacia.

\section{RESULTADOS E DISCUSSÃO}

\section{Caracterização Físico-Climática da Bacia}

O mapa de relevo da Bacia Hidrográfica do Rio Itapicuru-BA pode ser visualizado na Figura 03.

Figura 3 - Aracaju (SE): Modelo Digital de Elevação da BHRI derivado do SRTM, 2019.

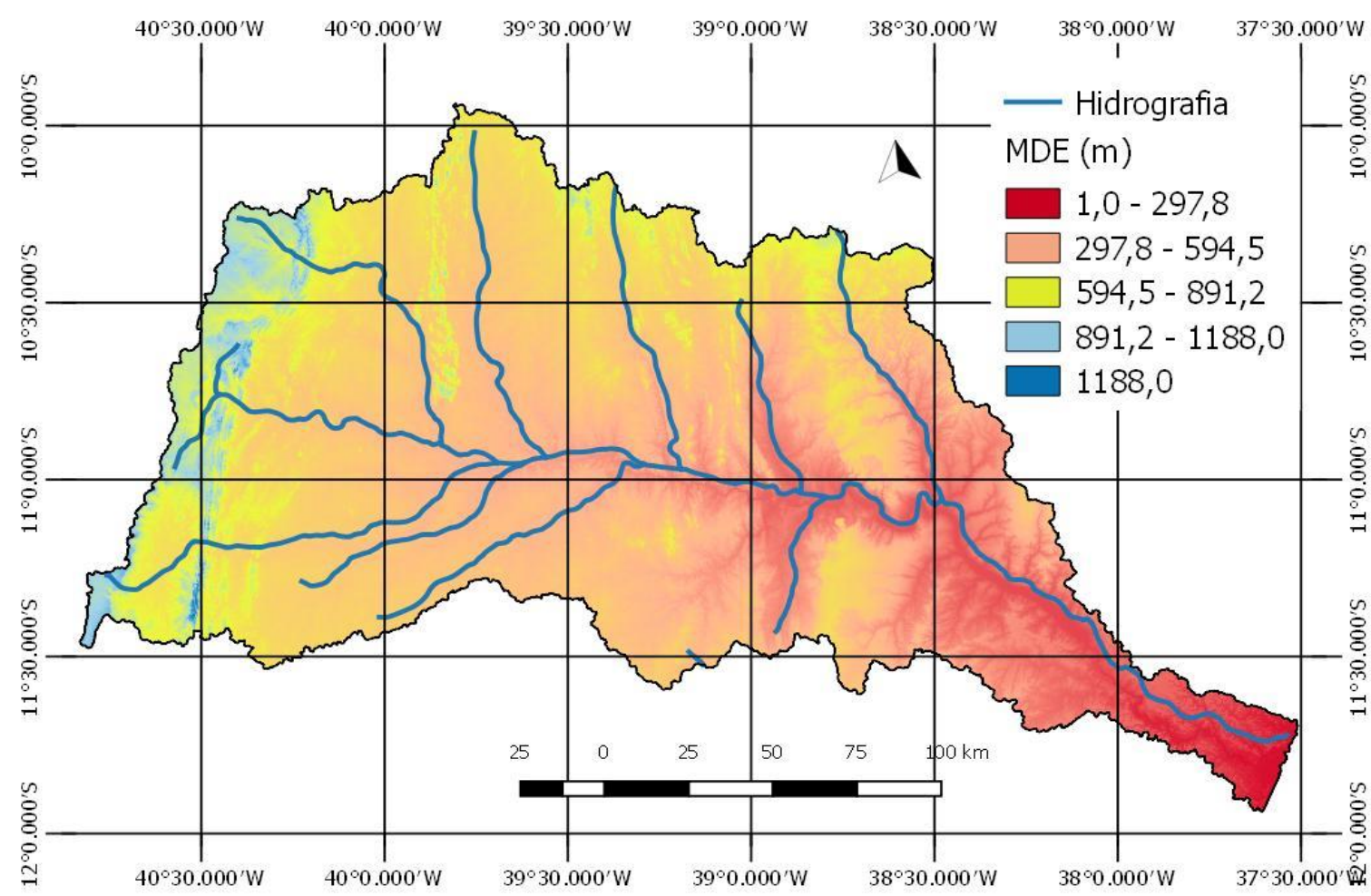

Fonte - Autores (2019).

Nota-se que o relevo da bacia é bastante acidentado, com valores de altitude próximos de zero na foz e valores acima de 1000 metros na região de cabeceira. O relevo da bacia é uma das principais características físicas que interferem no comportamento hidrológico dos seus cursos d’água. Esta bacia caracteriza-se com relevo acidentado, apresentando uma elevada capacidade de acelerar o escoamento superficial nos canais de drenagem. Cabe ressaltar que esta não é a única característica física da bacia que interfere nesses processos, podendo destacar o uso e cobertura da terra e suas características morfológicas, como área de drenagem, fator de forma, dentre outras. A variação dos valores de altitude dentro da bacia, também pode influenciar na definição das regiões hidrologicamente homogêneas. Para Purificação et al., (2016), esse resultado é devido, principalmente, ao fato do elemento fisiográfico chamado geomorfologia, que configura a dinâmica da água em superfície e contribui para a caracterização do relevo existente. Outro fator, que caracteriza os valores de altitude, são as formações do relevo, que situa a nascente em trechos formados por pediplano cimero da chapada Diamantina, por planaltos Karsticos e por serras maciças residuais, e a foz formada por mares de morro (RADAMBRASIL, 1983; PURIFICAÇÃO et al., 2016).

Corroborando aos resultados deste trabalho, Virães (2013) verifica a semelhança dos resultados através do traçado do perfil longitudinal da bacia hidrográfica que determina as mais altas altitudes 
Definição de regiões hidrologicamente homogêneas a partir de técnicas de estatística multivariada na Bacia Hidrográfica do Rio Itapicuru - BA com base em dados físico-climáticos e de sensoriamento remoto
Ytallo Rafaell Teixeira de Albuquerque André Quintão de Almeida Mariana Stocco Arcieri Ludmilson Abritta Mendes

em cerca de 800 m na sua porção ao oeste, região da nascente, e valores inferiores, próximos de zero, na região ao leste.

A Tabela 01 demonstra os valores das características físico-climáticas utilizadas neste trabalho, apresentando seus valores mínimos, médios e máximos coletados na região da BHRI.

Tabela 1 - Aracaju (SE): Caracterização físico-climática da Bacia Hidrográfica do Rio Itapicuru, 2019.

\begin{tabular}{lccccc}
\hline Valor & $\mathbf{P}\left(\mathbf{m m ~ a n o}^{-1}\right)$ & $\mathbf{E T 0}\left(\mathbf{m m ~ a n o}^{-1}\right)$ & P ET0 $^{-1}$ & ALT (m) & NDVI \\
\hline Mínimo & 521,80 & 1555,00 & 0,29 & 1,00 & 0,30 \\
Médio & 747,30 & 1651,00 & 0,45 & 405,70 & 0,50 \\
Máximo & 1523,00 & 1814,00 & 0,98 & 1188,00 & 0,68
\end{tabular}

P, precipitação; ET0, evapotranspiração potencial; ALT, a altitude; e NDVI, índice da diferença normalizada da vegetação.

$$
\text { Fonte - Autores (2019). }
$$

A bacia apresenta uma variação de precipitação significativa, com diferença entre os extremos de aproximadamente $1000 \mathrm{~mm}$. Os maiores valores de chuva ocorrem na região mais baixa da bacia e os menores na região mais elevada, clima semiárido. Isso se explica pelo fato de a bacia estar situada em três variações de zonas climáticas (zona tropical, a zona seca e a zona subtropical úmida) de acordo com a classificação climática de Köppen (ALVARES et al., 2013). Em conformidade com Purificação et al. (2016); Silva e Fontes (2017) corroboram que nas regiões próximas a serra de Jacobina, na porção sudoeste da bacia, a pluviosidade alcança até $1000 \mathrm{~mm}$ anuais, fazendo parte da zona tropical com verão seco (As); nas regiões próximas à costa, mais próxima à foz, encontramse as zonas tropical sem estação seca (Af) e monção (Am), com pluviosidade podendo atingir valores de $1500 \mathrm{~mm} / \mathrm{ano}$; e na região de menor pluviosidade, na porção central desta bacia, a pluviosidade varia de 400 a $600 \mathrm{~mm}$ anuais, fazendo parte da zona seca do semiárido de baixa latitude e altitude (BSh).

A demanda evapotranspirativa da bacia é bastante elevada, com valores mínimos de evapotranspiração potencial (ET0) próximos de $1500 \mathrm{~mm}^{2}$ ano $^{-1}$ e máximos próximos de $1800 \mathrm{~mm}$ $a_{n}{ }^{-1}$. Para Pereira et al. (1997), a quantidade de água evapotranspirada depende principalmente do suprimento de água às plantas, do poder evaporante do ar e da disponibilidade de energia de cada região. Virães (2013) e Brito (2007) observaram uma diferença significativa na evaporação média anual, de $1.847 \mathrm{~mm}$, definindo-a como relativamente alta, estando dentro da faixa típica de uma região semiárida.

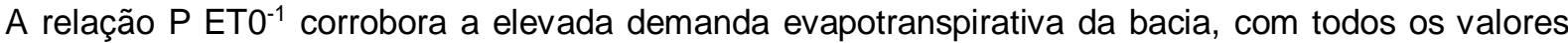
abaixo da unidade, ou seja, os valores de ETO ao longo do ano são superiores ao precipitado, evidenciando a importância de estudos que busquem a segurança hídrica na bacia. No Estado do Ceará, Rocha et al. (2017) observaram uma maior correlação negativa no primeiro semestre, acima de $70 \%$ para janeiro, fevereiro e abril, quando comparado com o segundo, entre $39 \%$ e $56 \%$, isso se deve ao fato que os meses com menores precipitações resultam em maiores valores de ET0, devido à variação dos valores de ET0 da região.

Os valores de NDVI variaram entre 0,3 e 0,67, uma variação de quase 0,4. Cabe destacar que os valores de NDVI refletem o vigor da vegetação, sendo, portanto, uma variável importante na definição de regiões hidrologicamente homogêneas na bacia. Podendo ser uma variável importante em estudos de definição de regiões homogêneas com a finalidade de geração de equações de regionalização de vazões. De acordo com Gameiro et al. (2016), avaliando a cobertura vegetal por meio NDVI na SubBacia Hidrográfica do Baixo Jaguaribe - CE, no período úmido (15/05/2015), observaram os valores de 0,5 NDVI, a mesma média do valor encontrado neste trabalho para a BHRI, isso explica-se devido à presença de uma vegetação com mais folhas na região, resultado da boa disponibilidade de água no solo, que proporcionou melhores condições no desenvolvimento da vegetação nativa e das áreas agricultáveis. Já Almeida et al. (2012) fazem a classificação da vegetação de Caatinga com baixo 
Definição de regiões hidrologicamente homogêneas a partir de técnicas de estatística multivariada na Bacia Hidrográfica do Rio Itapicuru - BA com base em dados físico-climáticos e de sensoriamento remoto
Ytallo Rafaell Teixeira de Albuquerque André Quintão de Almeida Mariana Stocco Arcieri Ludmilson Abritta Mendes

nível de alteração ambiental e degradação em arbóreo-arbustiva fechada (NDVI entre os níveis 0,43 a 0,81 ) e arbustivo-arbórea fechada (NDVI entre 0,25 a 0,32 ), sabendo-se que a grande região central da BHRI é caracterizada por predominar as pastagens entremeadas por áreas com vegetação de Caatinga (INEMA, 2018), podendo ser um dos fatores dos valores de NDVI encontrados na BHRI. Recomenda-se necessário o maior aprofundamento em estudos que desenvolvam e comprovem a qualidade desta variável neste tipo de estudo, haja vista as poucas fontes de informação que abordam sobre esta variável.

\section{Regiões Hidrologicamente Homogêneas}

A Figura 04 mostra o dendrograma obtido pelo método de agrupamento Hierarchical k-means clustering (hkmeans), com a distância como medida de similaridade e apresentando os dados de clima dos anos de 1980 a 2013 e dados de NDVI dos anos de 2000 a 2017 como as variáveis de agrupamentos nos 82 pontos da grade meteorológicas na área de estudo. O eixo das ordenadas mostra a distância, em que, quanto maior seu valor, maior a heterogeneidade dos dados das estações agrupadas. O número de grupos foi determinado de maneira subjetiva, selecionando e agrupando os pontos de grade com maior similaridade entre as características físico-climáticas e de vegetação em grupos, através de um corte transversal no dendrograma resultante do agrupamento. Considerando o nível de heterogeneidade, bem como a distribuição espacial dos pontos meteorológicos, foi adotada a distância de 7 para a definição do número de grupos, gerando-se três regiões homogêneas. Vale ressaltar que todas as variáveis tiveram mesmo peso quanto a definição do agrupamento.

Figura 4 - Aracaju (SE): Dendrograma obtido pelo método hkmeans, 2019.

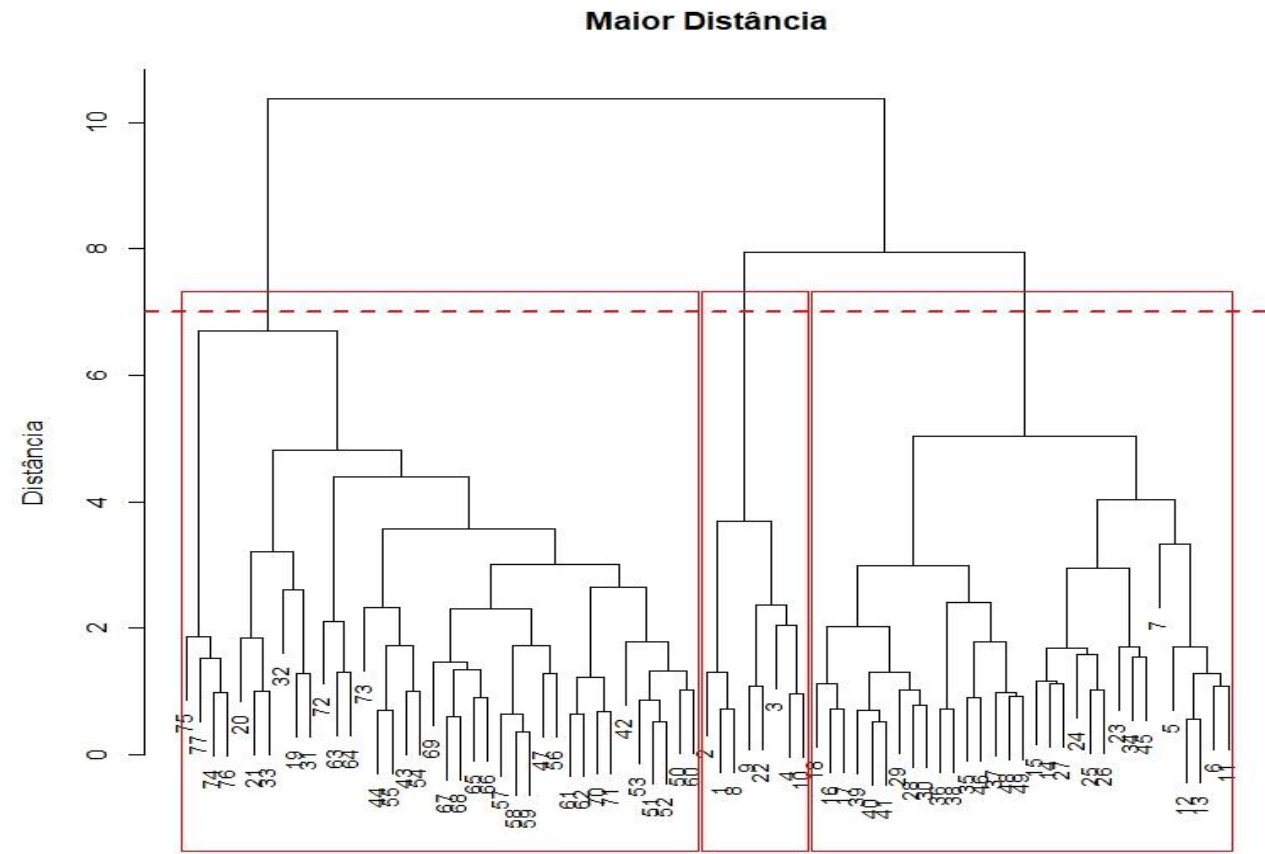

Pontos de grade

Fonte - Autores (2019).

Um fato importante que pode estar relacionado a esse resultado, encontra-se no fato de o desempenho do agrupamento hierárquico ser melhorado pelo algoritmo k-means, em comparações feita por Galili (2016), entre clustering hierárquico e abordagem híbrida. Dessa forma, procede-se ao uso de método híbrido, com a finalidade de minimizar o esforço necessário para identificar regiões

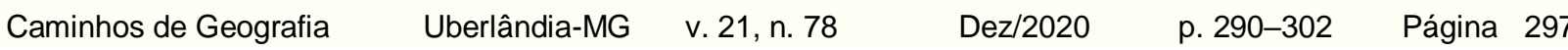


Definição de regiões hidrologicamente homogêneas a partir de técnicas de estatística multivariada na Bacia Hidrográfica do Rio Itapicuru - BA com base em dados físico-climáticos e de sensoriamento remoto
Ytallo Rafaell Teixeira de Albuquerque André Quintão de Almeida Mariana Stocco Arcieri Ludmilson Abritta Mendes

homogêneas, fornecendo flexibilidade suficiente e oferece perspectivas de melhoria nos estudos de regionalização (RAO; SRINIVAS, 2006).

A Figura 05 mostra o refinamento da análise e a disposição espacial dos três grupos definidos após a aplicação do método hkmeans, com a hidrografia percorrendo todas as regiões determinadas. Observa-se que a Região I abrangeu a área de maior altitude e parte central do mapa da bacia hidrográfica do rio Itapicuru, onde essas áreas apresentam semelhança no revelo, vegetação e na precipitação média anual. A região II cobriu um relevo mais estável, caracterizado entre plano e suave ondulado, e apresentou os valores mínimos de precipitação média anual comparado com as demais regiões. Já a região III abrangeu um relevo misturado e apresenta maior valor de precipitação média anual, envolvendo, também, a região da foz do rio principal, que sofre a influência dos efeitos de região litorânea.

Figura 5 - Aracaju (SE): Regiões Homogêneas de clima na BHRI, 2019.

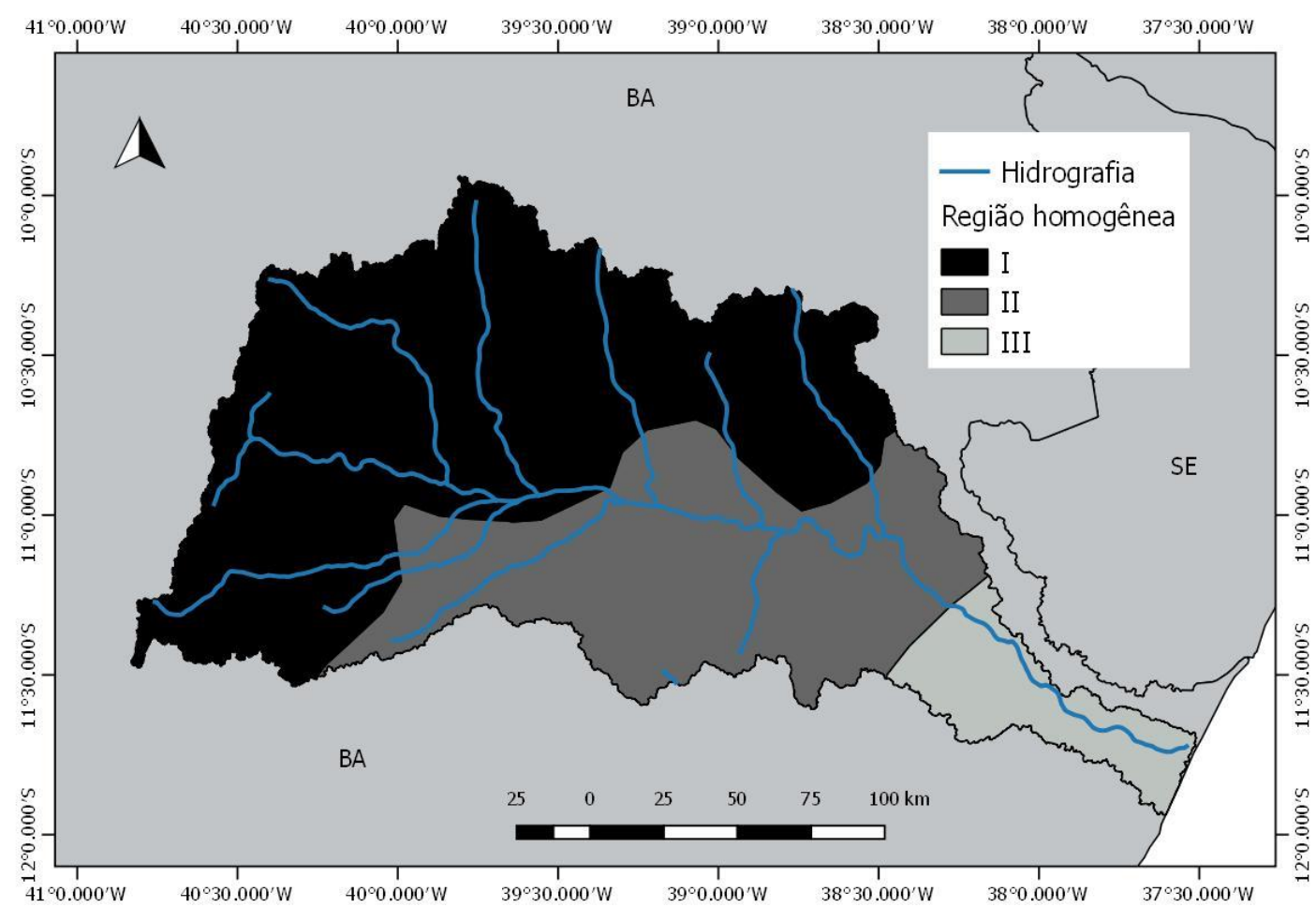

Fonte - Autores (2019).

Corroborando ao resultado apresentado, o corolário de Virães (2013) apresentou-se semelhante ao que se obteve neste trabalho. A área que compreende a Bacia Hidrográfica do Rio Itapicuru também foi dividida em três regiões, à foz, ao centro e à nascente, concernindo ambos os resultados.

Por outro lado, Chaves et al. (2002) diferem desses resultados, uma vez que a região da mesma bacia hidrográfica foi dividida em apenas duas regiões homogêneas. Este fato se deve em função do pequeno número de postos fluviométricos utilizados no estudo, apenas quatro, e, além disso, ter usado apenas uma variável explicativa, a área. Ambas as limitações devem ter contribuído para a menor precisão adquirida.

A Tabela 02 apresenta a precipitação e a evapotranspiração média anual, respectivamente, de cada região, para o período estudado, além das outras características físico-climáticas analisada no estudo. Fica evidente que, apesar de o comportamento médio das duas primeiras regiões seguirem uma mesma tendência mais próxima, ao longo dos anos, a precipitação média anual da região II é sempre superior à da região I. No entanto, em média, a precipitação anual da região III é mais que o dobro em relação aos demais grupos. 
Definição de regiões hidrologicamente homogêneas a partir de técnicas de estatística multivariada na Bacia Hidrográfica do Rio Itapicuru - BA com base em dados físico-climáticos e de sensoriamento remoto
Ytallo Rafaell Teixeira de Albuquerque André Quintão de Almeida Mariana Stocco Arcieri Ludmilson Abritta Mendes

Tabela 2 - Aracaju (SE): Caracterização físico-climática da Bacia Hidrográfica do Rio Itapicuru por regiões Homogênea, 2019.

\begin{tabular}{|c|c|c|c|c|c|c|c|c|c|}
\hline \multirow{3}{*}{ Variável } & \multicolumn{9}{|c|}{ Grupo (Cluster) } \\
\hline & \multicolumn{3}{|c|}{ I } & \multicolumn{3}{|c|}{ II } & \multicolumn{3}{|c|}{ III } \\
\hline & Med. & Max. & Min. & Med. & Max. & Min. & Med. & Max. & Min. \\
\hline Chuva (mm) & 629,56 & 751,63 & 532,35 & 685,60 & 1007,74 & 521,84 & 1266,79 & 1522,97 & 1003,35 \\
\hline ETO (mm) & 1693,69 & 1814,01 & 1632,13 & 1627,01 & 1680,17 & 1558,13 & 1571,48 & 1590,57 & 1554,90 \\
\hline Chuva ET0-1 & 0,37 & 0,45 & 0,29 & 0,42 & 0,65 & 0,31 & 0,81 & 0,97 & 0,64 \\
\hline Altitude (m) & 568,21 & 1016,00 & 328,00 & 307,77 & 459,00 & 170,00 & 165,00 & 246,00 & 92,00 \\
\hline NDVI & 0,50 & 0,68 & 0,30 & 0,45 & 0,68 & 0,31 & 0,60 & 0,68 & 0,52 \\
\hline
\end{tabular}

Em relação à evapotranspiração, a região I apresenta valores superior às outras regiões, isso pode ser explicado pela área ser caracterizada por elevadas temperaturas e baixa umidade relativa, ao contrário da região III, que apresentar-se com valores mais baixos.

De todo modo, esses parâmetros climáticos afetam diretamente o rendimento hídrico das bacias hidrográficas, da umidade atmosférica, da determinação da capacidade de reservatórios, do regime de chuvas, entre outros, e para um melhor entendimento desses processos, seria necessário um estudo dos sistemas climáticos que influenciam as três regiões.

A Região I apresenta chuvas com média anual de $605 \mathrm{~mm}$ e evapotranspiração com média de 1.687 $\mathrm{mm}$. A Região II apresenta chuvas com média anual de aproximadamente $634 \mathrm{~mm}$ e evapotranspiração com média de $1.622 \mathrm{~mm}$. A Região III apresenta chuvas com média anual de $1.428 \mathrm{~mm}$ e evapotranspiração com média de $1.568 \mathrm{~mm}$.

Os valores das variáveis concernentes a cada região são característicos da posição geográfica que cada uma ocupa, que define as suas particularidades físico-climáticos.

\section{CONSIDERAÇÕES FINAIS}

O método de hkmeans, utilizando a distância como medida de similaridade, apresentou bons resultados na identificação de regiões homogêneas físico-climáticos e de vegetação (NDVI) para toda a Bacia Hidrográfica do Rio Itapicuru - BHRI.

A aplicação da técnica de agrupamento hierárquico combinado com o k-means, utilizando índices físico-climáticos e de vegetação evidenciou a existência de três regiões semelhantes na Bacia Hidrográfica do Rio Itapicuru. Em síntese essa técnica da análise multivariada mostrou-se como uma importante ferramenta para definição de diferentes regiões com maior ou menor potencialidades climáticas e de sensoriamento remoto para os diversos fins como na aplicação de regionalização de vazões, escolha de região para melhor cultivo de culturas de subsistência, entre outras.

Este agrupamento representou a realidade do comportamento climático das regiões homogêneas da bacia hidrográfica, podendo, dessa forma, contribuir com estudos futuros relacionados aos assuntos climáticos, que possam vir a ser realizados por acadêmicos, instituições e órgãos públicos, nesta região, fortalecendo, assim, o auxílio no planejamento e gestão dos recursos hídricos.

\section{AGRADECIMENTOS}

O presente trabalho foi realizado com apoio da Coordenação de Aperfeiçoamento de Pessoal de Nível Superior - Brasil (CAPES) - Código de Financiamento 001. Em adição, agradece-se ao Programa de Pós-Graduação em Recursos Hídricos da Universidade Federal de Sergipe pela estrutura física e oportunidade.

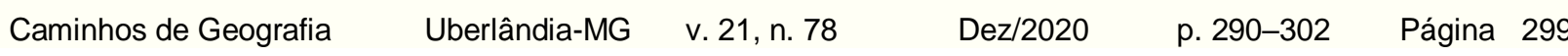


Definição de regiões hidrologicamente homogêneas a partir de técnicas de estatística multivariada na Bacia Hidrográfica do Rio Itapicuru - BA com base em dados físico-climáticos e de sensoriamento remoto
Ytallo Rafaell Teixeira de Albuquerque André Quintão de Almeida Mariana Stocco Arcieri Ludmilson Abritta Mendes

\section{REFERÊNCIAS}

ALMEIDA, N. V.; CUNHA, S. B.; NASCIMENTO, F. R. A cobertura vegetal e sua importância na análise morfodinâmica da bacia hidrográfica do rio Taperoá - Nordeste do Brasil/Paraíba. Revista Geonorte, Edição Especial, V.3, N.4, p. 365-378, 2012.

ALLEN, R.G.; PEREIRA, D. R.; RAES, D.; SMITH, M. 1998. Crop Evapotranspiration: Guidelines for Computing Crop Water Requirements, 1st edn. United Nations, FAO: Rome. Disponível em: http://www.kimberly.uidaho.edu/ref-et/fao56.pdf. Acesso em: 01/07/2018.

ALVARES, C.A.; STAPE, J. L. et al. (2013). Köppen's climate classification map for Brazil. Meteorologische Zeitschrift, v. 22, n. 6, p. 711-728. https://doi.org/10.1127/0941-2948/2013/0507

BRASIL. Lei no 9433, de 8 de janeiro de 1997. Institui a Política Nacional de Recursos Hídricos, cria o Sistema Nacional de Gerenciamento de Recursos Hídricos, regulamenta o inciso XIX do art. 21 da Constituição Federal, e altera o art. I da Lei no 8001, de 13 de março de 1990, que modificou a Lei no 7990, de 28 de dezembro de 1989. Diário Oficial da República Federativa do Brasil, Brasília, 9 jan. 1997.

BRITO, M. C. M. Qualidade da água para irrigação na bacia do rio Itapicuru e risco de salinização no projeto de irrigação Ponto Novo - BA. Dissertação (Mestrado em Engenharia e Manejo da Irrigação) - Universidade Federal do Recôncavo da Bahia, Cruz das Almas - Bahia, 2007.

CHAVES, H. M. L.; ROSA, J. W. C.; VADAS, R. G.; OLIVEIRA, R. V. T. Regionalização de vazões mínimas em bacias através de interpolação em sistemas de informações geográfica. Revista Brasileira de Recursos Hídricos, Porto Alegre, v.7, n. 3. p. 43-51, 2002. https://doi.org/10.21168/rbrh.v7n3.p43-51

CRA - Centro de Recursos Ambientais da Bahia. Bacia Hidrográfica do Rio Itapicuru. Salvador: 2001.

ELETROBRÁS: Centrais Elétricas Brasileiras. Metodologia para regionalização de vazões. Rio de Janeiro, v. 2, 1985.

EMBRAPA - Empresa Brasileira de Pesquisa Agropecuária. Brasil em Relevo. Disponível em: $<$ https://www.cnpm.embrapa.br/projetos/relevobr>. Acesso em 16 de dezembro de 2018.

EMBRAPA INFORMÁTICA AGROPECUÁRIA. Sistema de análise temporal da vegetação: SATVeg. Campinas, 2016.

EUCLYDES, H. P.; FERREIRA, P. A.; RUBERT, O. A.; SANTOS, R. M. Regionalização hidrológica na bacia do Alto São Francisco a montante da barragem de Três Marias, MG. Revista Brasileira de Recursos Hídricos, Porto Alegre, v.6, n.2, p.81-105, 2001. https://doi.org/10.21168/rbrh.v6n2.p81$\underline{105}$

GALILI, T. Hybrid hierarchical k-means clustering for optimizing clustering outputs Unsupervised Machine Learning. 2016. Disponível em: < https://www.r-bloggers.com/>. Acesso em: 10 de novembro de 2018.

GAMEIRO S.; TEIXEIRA C.P.B.; SILVA NETO T.A.; LOPES M.F.L.; DUARTE C.R.; SOUTO M.V.S.; ZIMBACK C.R.L. Avaliação da cobertura vegetal por meio de índices de vegetação (NDVI, SAVI e IAF) na Sub-Bacia Hidrográfica do Baixo Jaguaribe, CE. Terræ, 13(1-2):15-22, 2016.

GOMES, E. P.; BLANCO, C. J. C.; PESSOA, F. C. L. Regionalization of precipitation with determination of homogeneous regions via fuzzy C-means. Brazilian Journal of Water Resources RBRH, Porto Alegre, v. 23, e51, 2018. https://doi.org/10.1590/2318-0331.231820180079

INEMA: Instituto do Meio Ambiente e Recursos Hídricos. Comitê da Bacia Hidrografica do rio Itapicuru. Disponível em: < http://www.inema.ba.gov.br/gestao-2/comites-de-bacias/comites/cbhitapicuru>. Acesso em: 03/09/2018.

IBGE. (2011) - Instituto Brasileiro de Geografia e Estatística. Disponível em: $<$ http://www.ibge.gov.br>. Acesso em: 03/09/2018.

LINDEN, R. Técnicas de Agrupamento. Revista de Sistemas de Informação da FSMA, n. 4, p. 1836, 2009. 
Definição de regiões hidrologicamente homogêneas a partir de técnicas de estatística multivariada na Bacia Hidrográfica do Rio Itapicuru - BA com base em dados físico-climáticos e de sensoriamento remoto
Ytallo Rafaell Teixeira de Albuquerque André Quintão de Almeida Mariana Stocco Arcieri Ludmilson Abritta Mendes

MORAIS, F. (2012) Infiltração - Uma variável geomorfológica. Universidade Federal do Tocantins - Porto Nacional. Disponível em: http://periodicos.pucminas.br/index.php/geografia/article/viewFile/3753/4389. Acesso em: 04 de agosto de 2018.

MORAES, M. B. C. Análise Multivariada Aplicada à Contabilidade. Notas de Aula. Mestrado e Doutorado em Controladoria e Contabilidade - USP, 2016.

NERC. Flood studied report. London, 1975, 50.

PEREIRA, A. R.; VILLA NOVA, N. A.; SEDIYAMA, G. C. Evapotranspiração. Piracicaba: FEALQ, 1997, $183 \mathrm{p}$

PESSOA, F. C. L. Desenvolvimento de Metodologia para Regionalização de Curvas de Permanência de Vazões na Amazônia Legal. Tese (Doutorado em Engenharia) - Programa de PósGraduação em Engenharia de Recursos Naturais da Amazônia, ITEC, Universidade Federal do Pará - UFP, Belém, 2015.

PURIFICAÇÃO, C. G. C.; SOARES, R. S.; JESUS, M. H.; SALLES, L. Q.; GONÇALVES, T. S. Hidrogeologia da bacia hidrográfica do rio Itapicuru - BA, como subsídio para o plano diretor de bacias. XIX Congresso Brasileiro de Águas Subterrâneas, Campinas - SP, 2016.

QGIS Development Team, 2019. QGIS Geographic Information System. Open Source Geospatial Foundation Project._Available at: http://qgis.osgeo.org. Acesso em: 09 de outubro de 2018.

R CORE TEAM. R. A language and environment for statistical computing. Vienna: R Foundation for Statistical Computing, 2015. Available at: http://www.R-project.org. Acesso em: 06 de setembro de 2018.

RADAMBRASIL, Ministério das Minas e Energia. Secretaria Geral. Projeto RADAMBRASIL. Folha SC. 24/25 Aracaju/Recife: Geologia, Geomorfologia, Pedologia, Vegetação e Uso Potencial da Terra. Rio de Janeiro, 1983. 624p.

RAO, A. R.; SRINIVAS, V. V. Regionalization of watersheds by fuzzy cluster analysis. Journal of Hydrology, v. 318, n. 1-4, p. 57-79, 2006. https://doi.org/10.1016/j.jhydrol.2005.06.004

RAO, A. R.; SRINIVAS, V. V. Regionalization of watersheds by hybrid cluster analysis. Journal of Hydrology, v. 318, n. 1-4, p. 37-56, 2006.

ROCHA, R. V.; SOUZA FILHO, F. A.; SILVEIRA, C. S. Análise da relação entre evapotranspiração potencial e precipitação e do seu impacto nas vazões simuladas pelo modelo smap no Estado do Ceará. XXII Simpósio Brasileiro de Recursos Hídricos - ABRH, Florianópolis - SC, 2017.

ROUSE, J. W.; HAAS, R. H.; SCHELL, J. A.; DEERING, D. W. Monitoring vegetation systems in the great plains with ERTS. In 3rd ERTS Symposium, NASA SP-351 I. Washington, D.C.: NASA; 1973. 309-317.

SREEDEVI, P. D. et al. Morphometric analysis of a watershed of South India using SRTM data and GIS. Journal Geological Society of India, v. 73, n. 4, p. 543-552, 2009. https://doi.org/10.1007/s12594-009-0038-4

SILVA, A. C. G. Identificação de regiões hidrologicamente homogêneas por agrupamento fuzzy c-means no Estado do Paraná. Dissertação (Mestrado em Engenharia Agrícola) - Universidade Estadual do Oeste do Paraná, Cascavel, PR, 2018, 90 f.

SILVA, E. S.; FONTES, A.S. Importância ecológica do comportamento hídrico do rio Itapicuru no semiárido baiano. XXII Simpósio Brasileiro de Recursos Hídricos - ABRH, Florianópolis - SC, 2017.

SRINIVAS, V. V.; TRIPATHI, S.; RAO, A. R.; GOVINDARAJU, R. S. Regional flood frequency analysis by combining self-organizing feature map and fuzzy clustering. Journal of hydrology. v. 348, p. 148166, 2008. https://doi.org/10.1016/j.jhydrol.2007.09.046

VIRÃES, M. V. Regionalização de Vazões nas Bacias Hidrográficas Brasileiras: estudo da vazão de $95 \%$ de permanência da sub-bacia 50 - Bacias dos rios Itapicuru, Vaza Barris, Real, Inhambupe, Pojuca, Sergipe, Japaratuba, Subaúma e Jacuípe. Recife: CPRM, 2013. 
Definição de regiões hidrologicamente homogêneas a partir de técnicas de estatística multivariada na Bacia Hidrográfica do Rio Itapicuru - BA com base em dados físico-climáticos e de sensoriamento remoto
Ytallo Rafaell Teixeira de Albuquerque André Quintão de Almeida Mariana Stocco Arcieri Ludmilson Abritta Mendes

XAVIER, A. C.; KING, C. W.; SCANLON, B. R. Daily gridded meteorological variables in Brazil (19802013). International Journal of Climatology, v. 36, p. 2644-2659, 2016. https://doi.org/10.1002/joc. 4518

Recebido em: 06/03/2020

Aceito para publicação em: 11/08/2020 